\title{
Etc. The Long-Lasting Defining Device: Unravelling the Mystery ${ }^{\mathrm{i}}$
}

\author{
Safi Eldeen Alzi'abi, English Department, Jerash University, \\ Jerash,Jordan(alziabi@gmail.com)
}

\begin{abstract}
In its abbreviated form, 'etc.' is a lexicographic device that dates back to the early 15th century. It is used on a large scale in monolingual dictionaries for native speakers and EFL learners to serve a wide range of linguistic patterns. Unfortunately, there seems to be little research on the way this linguistic unit has been used, despite the fact literature abounds with details about dictionary making.

This descriptive analytical study reveals the way 'etc.' is used in EFL learner's dictionaries and brings to light some unknown evidence regarding its frequency of occurrence. The bald statistics prepared on the use of 'etc.' in the macrostructure and microstructure of a cross-section of four learner's dictionaries show that it has been widely used, but in many cases it seems dispensable. Analysis of a large body of definitions shows that 'etc.' appeared in the definitions of headwords of all word classes and sometimes more than once in many senses of polysemous lexical items in the range of one to five lexemes preceding 'etc.'

This widespread use of 'etc.' may place additional pressure on dictionary users in their desperate attempt to comprehend the definitions. Maybe it is high time that 'etc.' is considered outworn or obsolete and is replaced with something that lends itself to this age of modern technology, where space is no longer a major concern for dictionary makers.
\end{abstract}

Keywords: LEARNER'S DICTIONARIES, DEFINING TECHNIQUES, STYLE GUIDES, PATTERNS OF 'ETC.', 'ETC.' IN ELECTRONIC DICTIONARIES, DEFINITIONS WITH 'ETC.', FREQUENCY OF OCCURRENCE OF 'ETC.', ITEMS BEFORE 'ETC.'

Opsomming: 'Etc.' Die lank bestaande definiëringshulpmiddel: Die ontrafeling van die misterie. In sy afgekorte vorm is 'etc.' 'n leksikografiese hulpmiddel wat terugdateer tot vroeg in die 15de eeu. Dit word op groot skaal in eentalige woordeboeke vir moedertaalsprekers en EVT-leerders gebruik om 'n wye verskeidenheid taalpatrone te dien. Ongelukkig blyk daar min navorsing te wees oor die manier waarop hierdie taalkundige eenheid gebruik is, ten spyte daarvan dat daar 'n oorvloed literatuur is met besonderhede van woordeboekmaak.

Hierdie beskrywende analitiese studie dui die manier waarop 'etc.' gebruik word in EVTaanleerderwoordeboeke aan en lê onbekende bewyse bloot oor die frekwensie waarmee dit voorkom. Die onverwerkte statistiek rakende die gebruik van 'etc.' in die makro- en mikrostruktuur van 'n deursnee van vier aanleerderwoordeboeke toon dat dit wyd gebruik is, maar dat dit in baie gevalle weggelaat kan word. Die ontleding van 'n groot groep definisies toon dat 'etc.' voorgekom het in die definisies van trefwoorde van alle woordklasse en soms meer as een keer in baie betekenisse van polisemiese leksikale items in die bestek van een tot vyf lekseme wat 'etc.' voorafgaan het.

Hierdie algemene gebruik van 'etc.' mag bykomende druk plaas op woordeboekgebruikers in hulle desperate poging om die definisies te verstaan. Miskien is dit hoog tyd dat 'etc.' as ver- 
ouderd en uitgedien beskou word en met iets vervang word wat homself leen tot hierdie tydperk van die moderne tegnologie, waar ruimte nie langer 'n groot oorweging is vir woordeboekmakers nie.

Sleutelwoorde: AANLEERDERSWOORDEBOEKE, DEFINIËRINGSTEGNIEKE, STYLGIDSE, 'ETC.'-PATRONE, 'ETC.' IN ELEKTRONIESE WOORDEBOEKE, DEFINISIES MET 'ETC.', VOORKOMSFREKWENSIE VAN 'ETC.', ITEMS VOOR 'ETC.'

\section{Introduction}

Dictionary definitions illustrate meanings by describing the reference relations of lexical items (Jackson 2002: 70). The explicit accounts of the meaning of lexemes inform dictionary users about the way the lexemes are used in some contexts within a language community. But the process of defining lexemes is very delicate and requires consummate professional skill. Lexicographers are therefore under considerable pressure to develop elegant ways to define word; the definitions have to be both intelligible and easily accessible in order not to mislead the user.

To describe and disambiguate the variant senses of headwords, lexicographers use several defining styles (see Geeraerts 2003 and Osselton 2007). The one most commonly used is the 'analytical' or 'descriptive' style (Ayto 1983: 90 and Zgusta 1971: 258). Generally, it uses a 'genus', the superordinate concept, the broad semantic category to which the lexeme belongs, and the 'differentia', the characteristics and the additional distinctive features typical of the genus; the format is often an incomplete sentence (Moerdijk 2003). The Oxford Advanced Learner's Dictionary, 8th edition, (OALD), for example, defines a hydrangea as "a bush with white, pink or blue flowers that grow closely together in the shape of a large ball". Here, bush is the genus and the differentia, "with white, pink or blue flowers", post-modifies it and distinguishes a hydrangea from a(n) 'broom', 'blackthorn' or 'azalea'. Similarly, bush is defined by another genus, plant, and it is differentiated from other members of the plant category by such distinguishing features as "growing quickly with several hard stems".

The analytical style is appropriate for defining a great many lexemes of most parts of speech, mainly concrete ones. However, lexicographers sometimes face problems with some lexemes such as abstract items (cf. Dziemianko and Lew 2006), which are not readily defined analytically. They therefore resort to defining by means of synonyms (see Van der Meer 2004). This is characterised by the inclusion of a single synonym, a set of synonyms or a synonymous phrase. Consider the definitions of worsen in Longman Dictionary of Contemporary English, 6th edition, (LDOCE) and OALD, respectively.

worsen: to become worse or make something worse

worsen: to become or make sth worse than before

A third defining technique delineates the function or use of the lexeme and this fits 'grammatical' words such as auxiliary verbs, conjunctions, determiners, 
prepositions and pronouns (see Atkins and Rundell 2008 and Jackson 2002). The following definition from Cambridge Advanced Learner's Dictionary, third edition, (CALD) indicates the function of 'and':

and: used to join two words, phrases, parts of sentences or related statements together ...

Other defining styles are in use (see Lew 2013; Lew and Dziemianko 2006a, $2006 \mathrm{~b}$ and 2012 and Rundell 2006) and each proves an effective defining strategy for a particular set of lexemes. Generally, all defining techniques seem to commonly make use of some devices to sensibly describe the different meanings of lexemes including parentheses, a largely used style in earlier editions of learner's dictionaries, and 'etc.' Hanks (1987: 116) asserts that "Over the years a number of conventions have grown up governing the ways in which dictionaries traditionally explain meaning ... For example of, or pertaining to, any of, various, etc., and esp. are extremely common in dictionaries ...".

According to Atkins and Rundell (2008: 437), one prime function of parentheses was "to indicate a word's 'selectional restrictions' (a verb's usual range of subjects or objects, or an adjective's typical complements) ...". Consider the examples below.

bijou: (of a building or a garden) small but attractive and fashionable OALD

break: to (cause something to) separate suddenly or violently into two or more pieces, or to (cause something to) stop working by being damaged CALD

In the first example, the parentheses specify the normal range of nouns modified by the adjective. These suggest that bijou is used with nouns such as 'house', 'shop', 'restaurant', 'apartment', 'cafes', 'bars', which are hyponyms of the superordinate 'building', and so on. In the second example, they indicate that break is an ergative verb in this sense. If the words in parentheses are suppressed, break is intransitive but if the parentheses themselves were removed, it would be a transitive verb (see also Atkins and Rundell 2008). Apparently, there may be a wide range of subjects or objects which occur with a certain sense of any verb to the extent that lexicographers cannot account for the full contextual variability in the definition. They therefore tend to list some of them and use 'etc.' to stand for the remainder, mostly under the pretext of being economical.

The linguistic unit 'etc.' is used extensively in monolingual dictionaries both in the definitions and examples. It is the intention of this study to reveal the way 'etc.' is used in EFL learner's dictionaries and provide some reliable statistics on the frequency of this usage ${ }^{\mathrm{ii}}$. The focus here is on dictionaries for learners because native speakers may find no difficulty handling definitions with 'etc.' and are able to infer the sense from the list preceding 'etc.', while learners may struggle to make the necessary connections. The study also outlines the different patterns 'etc.' represents in the definitions. Then light is shed on some relevant definitions of 'etc.' to discuss some of the reasons underlying 
the inclusion of this device. The study proper then follows, and the final section considers some pedagogical issues and recommendations.

\section{What 'etc.' means}

Etymologically speaking, this is a Latin term which is made up of et, "and", and cetera, "the rest", or more literally, "the other things". It is commonly abbreviated to 'etc.' but according to Peters (2004), the full spelling, 'et cetera', though rarely used, would also do. Let us see what dictionaries tell us about 'etc.'

Almost all dictionaries demonstrate that 'etc.' is primarily used at the end of a list to indicate that there are more things, objects, people, events, situations or items which could have been mentioned but were omitted for brevity. Along the same lines, LDOCE states that 'etc.' is used when the writer wants to tell the reader that there are many other examples or things of the same kind or class. This is rather misleading because the items left in the list are not always of the same kind or semantic class. The above definition seems a common practice in all Longman lexicographic products. The Longman Language Activator, for instance, indicates that 'etc.' means "and others of a similar kind ..." Although this is true on the face of it, in many cases it is still at odds with what exists in dictionaries, where in reality the remaining items are not always of a similar kind (see Alzi'abi 1995). One advantage of the Activator's definition is that it justifies the reasons dictionary makers substitute 'etc.' for the remaining items on the list.

Recently, dictionaries seem to slightly modify the definition of 'etc.' but this has been in the direction of more ambiguity. Consider the following two definitions by Collins Cobuild dictionary products (COBUILD) (see references).

etc: ... indicates that there are other items, events or situations which you could mention if you had the time and space ... (1987)

etc: is used at the end of a list to indicate that you have mentioned only some of the items involved and have not given a full list (2012)

Undeniably, the first definition is much clearer than the second; the use of 'event' and 'situation' shows the range of cases 'etc.' may cover rather than leaving them open to deduction.

\section{Why use 'etc.'}

It is logical to ask whether lexicographers implement any coherent policy in their application of 'etc.' The dictionary definitions themselves provide the answer to this question. A full examination of some entries shows that no conscious policies have been established regarding the inclusion of 'etc.' (see also Alzi'abi 1995 and 2016). Lexicographers need to speak for themselves as to whether they have any definite underlying mechanism for using this device.

One plausible reason, particularly in paper dictionaries, is economy of 
space. Truly, the long list of lexemes covered by 'etc.' is space-consuming but the use of 'etc.' exacerbates users' problem in inferring the lexemes which fill this gap. This is not the sole reason, however. Having scrutinised a large number of definitions, one can discern that many of those containing 'etc.' were not written with the above reason in mind; rather the items covered by 'etc.' were simply too hard to provide or possibly the list of possibilities is too exhaustive and varied to allow for feasible inclusion (see examples in 4.3). In other words, the editors might find it hard to think of more items. This of course has been implicitly suggested in some definitions of 'etc.' Sometimes, it is possible that some writers use it because they know not of any more items to add. It is really a serious matter which could unduly affect the whole look-up process. This being the case, dictionary users will be completely frustrated and it undoubtedly adversely affects their comprehension and production skills. Some definitions with 'etc.' require skilled semanticists to provide other items to replace 'etc.' (see for example the definition of zest in LDOCE and OALD). One writeriii humorously remarks that 'etc.' is employed when writers run out of items and cannot think of anything else to add to the named ones rather than limiting the range of items provided.

One important issue deduced from the definitions of 'etc.' is that it is used when a fuller list of items is considered to be unnecessary. This at times may be true and many examples exist to substantiate this claim (see 4.3). The question however is: How can editors tell whether the fuller list is (un)necessary, specifically when the items covered by 'etc.' are collocates of another item in the definition? A really vexing matter here is that in many a case 'etc.' stands for no more than two other words, which could be easily included. A few more pages might be tolerable when the resulting definitions are clearer and unambiguous.

A noteworthy point here is that some definitions of 'etc.' indicate that the items before 'etc.' belong to the same semantic field or possibly have similar semantic features. On examining some random entries, it is obvious that some definitions have genus words or superordinates. CALD defines articulation as "the way in which you express your feelings and ideas, etc.", where the words 'feelings' and 'ideas', superordinates, belong to the same semantic field, under which many hyponyms can be subsumed. Likewise, OALD definitions of cannibalise as "to take the parts of a machine, vehicle, etc. and use them to repair or build another" and commandeer as "to take control of a building, a vehicle, etc. for military purposes during a war, or by force for your own use", use the genus or superordinate word 'vehicle', under which several hyponyms can be subsumed. Assumedly, editors expect users to provide superordinate items and co-hyponyms of these items unaided (Alzi'abi 2016). This claim has been asserted by Michael Rundell (p.c.), editor-in-chief of Macmillan Advanced Learner's Dictionary (MEDAL 2nd edition). Their Style Guide recommends using 'etc.' only sparingly; that is to say, when the editors expect users to be capable of working out from their own real-world knowledge the exact words which would replace 'etc.' Unfortunately, not all editors strictly adhere to such 
guidelines (see below). Other Style Guides might have similar guidance but unfortunately these were virtually inaccessible due to being commercially sensitive materials.

It may be true that dictionary makers use 'etc.' to represent some items when the criterion of classifying these items under a genus proved impossible. Alzi'abi (2016) argues that only a small number of definitions seem to conform to the above image of using 'etc.'; many are composite structures of both genus words and single items. When all the items belong to the same semantic field, dictionary users are less likely to be confused because they think of items along the lines of those included and vice versa (consider the definitions of the noun access and the verb sabotage in LDOCE and segue in OALD).

\section{The study}

\subsection{Aim}

The present study addresses the following issues:

1. To explore the way 'etc.' is used in EFL learner's dictionaries and identify the various functions it serves.

2. To estimate the number of headwords generally defined by means of 'etc.' in these dictionaries.

3. To compute the total occurrences of 'etc.' in the definitions of individual headwords as these differ from the above, where some definitions contain more than one 'etc.'

4. To check the average number of items which usually precede 'etc.' in the definitions.

\subsection{Method}

To be able to look at the way 'etc.' is employed in learner's dictionaries and identify the different patterns and structures for which 'etc.' stands, it was necessary to intensely scrutinise and carefully analyse the definitions, specifically the lexemes supplied by dictionary makers before 'etc.' Four dictionaries on DVDROM were closely examined: CALD, LDOCE, MEDAL and OALD. The fifth big learner's dictionary, COBUILD, was excluded as it did not apply 'etc.' in its definitions. Earlier versions, particularly the ones in print, used it very sparingly but since 1995 COBUILD contained none. This may reflect COBUILD editors' policy of frequently abandoning traditional techniques of lexicography (see Barnbrook and Sinclair 1995; Hausmann and Gorbahn 1989; Moon 2007 and Sinclair 1987).

As to 'etc.'-patterns, a rigorous examination of all entries containing this linguistic unit revealed that it had served several grammatical patterns and structures, including verbs followed by a list of adverbs or nouns plus 'etc.', or 
possibly adverbs followed by a number of adjectives plus 'etc.' and so on. However, only those commonly used functions in all four dictionaries were listed along with examples. Some other structures were also identified in the corpus but these were ignored as they prevailed only in one, two or three dictionaries. It is highly likely that some other patterns might have emerged had the entries in the remaining letter stretches been examined. A noteworthy point is that the examples cited below were random selections from the ones extracted. Moreover, for brevity, only examples from LDOCE are used, unless otherwise stated.

To give an approximate estimate of the use of 'etc.' all the headwords which utilise it in the definitions were identified using the Advanced Search facilities available, which at times offered some invaluable help. This task was not so easy in LDOCE. Exact figures could not be reached because its Advanced Search was difficult to use and the queries results were awkward to handle. (The figures obtained were therefore prone to errors and should be interpreted with this in mind). A calculation was made of all headwords whose definitions contained 'etc.', which of course did not give the actual occurrences of 'etc.'

Having come up with a basic idea about the number of headwords defined by means of 'etc.' in the four dictionaries, it has been tedious to work out the precise number of times - hundreds, perhaps thousands - 'etc.' has been used in all entries. To get a rough estimate for the number of times 'etc.' occurred in any dictionary, the entries of only two sections of the wordlist were considered as temporarily representative samples. The headwords beginning with the letters 'a' and 's' were randomly chosen. They however seemed to be among the largest sections of the wordlist in any English language dictionary, constituting approximately $20 \%$ of the dictionary's average size.

In order to collect evidence regarding the double or treble appearance of 'etc.' in definitions, a thorough examination was carried out of the definitions of the various senses of the headword in the two letter stretches. The figures of the exact number of definitions containing more than one sense defined by means of 'etc.' and the exact number of 'etc.'-occurrences were all computed. Comparing and contrasting these figures help determine which dictionary made much use of 'etc.' in any of the above cases.

To draw a comprehensive picture of the content of the 'etc.' segment in the definitions, i.e. the number of item(s) preceding 'etc.', the 3768 occurrences of 'etc.' in total (1007 in the 'a' section and 2761 in 's' section) were extracted, broken down and further lemmatised and manually tagged to get the total cases where 'etc.' was preceded by one, two, three, four and even five items. This helped establish the total number of each of these categories.

Before moving on to the next section, it is stressed the figures reported below do not involve the cases 'etc.' was used as an extension to lists in the examples and illustrative sentences. 


\subsection{Results and discussion}

Below is an account of the results of a quantitative analysis of dictionary definitions to find out more about the use of 'etc.'

\subsubsection{Etc. in dictionaries}

The linguistic unit 'etc.' seems to be used similarly in all dictionaries. One may think that it is used in the definitions of the highly-specialised or technical vocabulary, where possibly specialist users may know all the words covered by 'etc.' A cursory glance at any of the dictionaries reveals that 'etc.' is employed in the definitions of all types of vocabulary items of all parts of speech and sometimes used more than once in the same definition. Although dictionaries vary tremendously as to the number of lexemes whose definitions contain 'etc.', this device seems to occur at a rather alarming frequency (see Tables 1 and 2 below). A quick browse through paper dictionaries reveals that the average use of 'etc.' ranges between three and seven occurrences per page but it is not easy to explain the disparity which exists between dictionaries for native and nonnative speakers as to the number of times they apply 'etc.' in the definitions. Dictionaries for native speakers use 'etc.' on a larger scale. Randomly picked out, Chambers Pocket Dictionary (1992) showed that page 777 (revere $\rightarrow$ revive), randomly selected, had 20 occurrences of 'etc.', a quite large figure compared to those in learner's dictionaries. Most likely, dictionary compilers assume that native speakers are more able to infer the remaining possibilities covered by 'etc.' because of their own broader linguistic knowledge.

This device, i.e. 'etc.' is commonly used to represent a list of noun collocates (both in the subject and object positions), adverb collocates of verbs or adjective collocates of nouns, e.g. .iv $^{-}$

snowballs: if a problem, a plan, an activity, etc .snowballs, it quickly becomes much bigger, more serious, more important, etc

Moreover, it is applied in exemplification cases following expressions like "such as" and "for example". Consider these examples.

shopfitting: the process of preparing the inside of a shop by putting in equipment such as lights, shelves, etc. MEDAL

short-circuit: to prevent sth such as a career, plan, process, etc. from being successful MEDAL

slapstick: the type of humour that is based on simple actions, for example people hitting each other, falling down, etc. OALD

string sb along: to allow $\mathrm{sb}$ to believe sth that is not true, for example that you love them, intend to help them, etc. OALD

\subsubsection{Patterns of 'etc.' use}

A rigorous examination of entries containing 'etc.' revealed that 'it fulfilled 
several grammatical patterns and structures. Categorised below are the most commonly used functions and patterns along with illustrative examples. The bracketed plural suffix is added to the word classes for which 'etc.' stands.

It is worth reiterating that the patterns delineated below are those spotted most frequently in the two letter stretches under consideration. It is highly likely that other patterns would have emerged if the entries of the remaining sections had been examined. The examples cited are random selections from the corpus and, as indicated above, are all derived from LDOCE.

\subsection{Verbs/verb phrases}

Here 'etc.' stands for verbs which might be used with nouns or adverbs. In addition, it stands for some verb phrases or possibly whole clauses as shown below.

$\mathbf{V}(\mathbf{s})+\operatorname{Adv}(\mathbf{s})$ or $\operatorname{Adv}(\mathbf{s})+\mathbf{V}$ : The linguistic unit 'etc.' stands for a number of adverbs which qualify or modify the verb, either preceding the verb or following it, or in a number of cases, for verbs which occur with a particular adverb.

admit: ... freely, openly, frankly, etc. admit

$\mathbf{V}+\mathbf{N P ( s )}$ : This pattern has 'etc.' to represent a list of nouns which are the 'objects' of the defined verb, particularly when the verb is transitive.

superimpose: combine two systems, ideas, opinions, etc.

$\mathbf{V}(\mathbf{s})+\mathbf{P P}(\mathbf{s})$ : In this pattern, 'etc.' stands for prepositional phrases following particular verbs or possibly a list of verbs which are followed by prepositional phrases.

accede: to agree to a demand, proposal, etc.

Linking Verb+Adj(s): Here 'etc.' covers a list of adjectives used predicatively, adjectives following intensive or linking verbs.

seem: ... seem important/right/strange, etc. to somebody

Verb phrases: In such structures, 'etc.' accounts for some verbs or verb phrases. Sometimes, it covers a whole clause.

self-taught: having learned a skill or subject by reading about it, practising it, etc.

\subsection{Nouns}

Here 'etc.' stands mostly for a number of nouns which may be used with particular verbs or adjectives. 
$\mathbf{N}(\mathbf{s})+\mathrm{V}$ : These patterns have 'etc.' to stand for a list of nouns serving as the subject of the following verb, mostly when the verb is used intransitively.

abound: if a place, situation, etc. abounds with things ...

$\mathbf{N}+\mathbf{P r e p}+\mathbf{N}(\mathbf{s})$ : The linguistic unit 'etc.' is employed to represent some nouns in a prepositional phrase following a certain noun, mostly of the form $\mathrm{N}+\mathrm{of}+\mathrm{N}$.

aspect: one part of a situation, idea, plan, etc. that has many parts

List of nouns/numbers: In this pattern 'etc.' covers a number of nouns on the list usually preceded by some signal words like "such as", "for example" and "for instance".

acute: acute senses such as hearing, taste, touch, etc. // strike if a clock strikes one, two, six etc., its bell makes a sound once, twice, six times, etc.

\subsection{Adjectives/adjective phrases}

Here 'etc.' stands for a number of adjectives which either modify some nouns or are modified by some adverbs. The most common pattern is adj+noun(s), where 'etc.' represents nouns qualified by adjectives.

$\operatorname{Adj}(\mathbf{s})+\mathbf{N}(\mathbf{s})$ : This pattern has 'etc.' to represent some nouns modified by a particular adjective or some adjectives which modify particular nouns.

subtle: ... subtle taste/flavour/smell, etc.

Adj(s)+Prep+N(s): In such a structure 'etc.' covers some nouns which are objects of prepositions following particular adjectives or some adjectives followed by prepositional phrases.

shadow: ... afraid/frightened/scared, etc. of your own shadow

Adj(s)+Prep+V(s): The linguistic unit 'etc.' here represents some adjectives which are followed by a preposition, mostly 'to' or 'for', plus verbs or verbs which usually follow some adjectives.

suitable: ... suitable to use/be shown, etc. // safe: safe to use/drink/eat, etc.

List of adjectives: This pattern has 'etc.' to stand for a number of adjectives used in a particular context and are used either attributively, i.e. before a noun or predicatively.

superior: better, more powerful, more effective, etc. than a similar person

In addition, 'etc.' in some structures represents some adjectives in similes, usually preceded by 'as' but this was more prevalent in sections other than the two under scrutiny. LDOCE, for example, has instances such as (anything 7: as 
important/clear/big, etc. as anything informal extremely important, clear etc.). OALD presents (seraphic: as beautiful, pure, etc. as an angel and anything: as happy, quick, etc. as anything [informal] very happy, quick, etc.). Similarly MEDAL has (subhuman: not as intelligent, kind, etc. as you think humans should be).

\subsection{Adverbs/adverb phrases}

In these patterns, 'etc.' stands for a number of adverbs which may modify some adjectives, i.e. $\operatorname{Adv}(\mathrm{s})+\operatorname{Adj}(\mathrm{s})$.

aware: politically/socially/environmentally, etc. aware

Analysis of the definitions has shown other patterns but these were not spotted in all dictionaries.

\subsection{Prepositional phrases}

In some cases, 'etc.' represents a list of prepositional phrases or nouns, adjectives and gerunds as propositional objects as well as prepositions or particles.

abstract: containing the most important ideas or points from a speech, article, etc.

\subsection{Wh-Words}

Here, 'etc.' represents a list of 'wh-words' following some verbs or used in noun phrases, occasionally in exclamatory sentences. However, these have not been traced in the entries within the two-letter stretches under scrutiny, viz. 'a' and 's' in some dictionaries. Many examples of such cases however existed in the remaining sections of the wordlist, i.e. other letter stretches.

ascertain: ascertain whether, what, how, etc; assess: assess what, how, etc.; say: say who, what, how, etc.; see: ... see why, what, how, etc.; suggest: suggest how, where, what, etc.

\subsection{Idioms}

Here 'etc.' is used in the definition of idioms and serves to represent several similar structures to the ones outlined above including verb phrases, noun phrases, adjective phrases and so on. No examples were cited in OALD, nonetheless.

VPs- shit: ... beat/kick, etc. the shit out of

NPs- shake: ... shake sb's confidence/beliefs, etc.

APs- shift: be on the late/early/night, etc. shift 


\subsubsection{Number of items defined by 'etc.'}

CALD has some 2150 lexical items whose explanations have 'etc.' These cover 1877 definitions, 200 phrases and 73 idioms. Filtering the queries further has shown the definitions belong to 939 nouns, 339 verbs, 236 adjectives, 16 adverbs and 8 prepositions. LDOCE comprises over 3500 nouns, 2000 adjectives, 1800 verbs, 250 adverbs, 60 prepositions and 60 pronouns whose explanations have 'etc.' Some of the occurrences of 'etc.' have been spotted in the definitions of the synonyms of the headword under THESAURUS. MEDAL has some 2042 items defined by means of 'etc.' including 237 phrases and idioms; they cover 808 nouns, 274 verbs, 300 adjectives, 51 adverbs, 24 prepositions, 18 pronouns, etc. As to OALD, the search results have been hard to tackle. The Oxford Dictionary Department (p.c.) report that OALD 9th edition has 7195 occurrences of 'etc.' in 5389 headwords. The figures suggest that multiple uses of 'etc.' occur in some entries. Additional queries have revealed that about 30\% of these items were nouns and a slightly smaller proportion was for verbs whereas adjectives amounted to about $12 \%$. Interestingly, matching entries from OALD 8th edition with those in the 9th edition has revealed additional headwords with 'etc.' in OALD 9 are mostly derivatives of some headwords (e.g. secretiveness, securely, simplistically, etc.). These are usually appended to the base forms in the 8th edition without any explanation. Generally, the figures above demonstrate beyond doubt that MEDAL relies the least on 'etc.' and LDOCE the most. Interestingly, MEDAL presents definitions with closed lists but the use of phrases such as "for example" and "for instance" saves the definitions from being over-restricted.

One might be really surprised at the large number of senses defined by means of 'etc.' in learner's dictionaries. The gravity of these instances can best be realised by knowing the total number of headwords in the dictionaries under scrutiny, which is not an easy task. The dictionaries advertise they have included a large number of words, phrases and meanings amounting to $(230,000)$ in LDOCE and $(185,000)$ in OALD compared to far fewer ones in CALD (68.119), according to the Cambridge Dictionaries Online Team (p.c.), and between 45,000 and 46,000 headwords in MEDAL, as reported by Michael Rundell (p.c.).

Table 1: Headwords defined with 'etc.' and actual occurrences of 'etc.' in the definitions

\begin{tabular}{llllll}
\hline & CALD & LDOCE & MEDAL & OALD $^{\mathbf{v}}$ \\
\hline Letter 'a' & $\begin{array}{l}\text { headwords defined with 'etc.' } \\
\text { occurrences of 'etc.' in defini- }\end{array}$ & 73 & 291 & 132 & 220 \\
& $\begin{array}{l}\text { Lions } \\
\text { Letter 's' }\end{array}$ & 455 & 207 & 261 \\
& $\begin{array}{l}\text { headwords defined with 'etc.' } \\
\text { occurrences of 'etc.' in defini- } \\
\text { tions }\end{array}$ & 234 & 624 & 196 & 723 \\
\hline
\end{tabular}


A thorough examination of entries in the two letter stretches in all dictionaries has shown the approximate figures (table 1) for the number of headwords whose definitions contained 'etc.' and the number of times 'etc.' arose in the definitions of the various senses of the items identified.

LDOCE and OALD included far more definitions with 'etc.' than the other two dictionaries, i.e. CALD and MEDAL in these particular letter stretches. Obviously, this is due to the comparatively larger number of headwords in these two letter stretches in both dictionaries. Knowing the approximate number of headwords in the two sections would display a clearer picture of 'etc.' usage in the four dictionaries. One possibly needs to have an idea about the ratio of the entries with 'etc.' to the total number of entries in the two sections. Table 2 below displays the total headwords in these letter stretches in all dictionaries ${ }^{v i}$, which enables us to reckon the ratio of definitions with 'etc.' to the headword list.

Table 2: No. of headwords in the two-letter stretches in all four dictionaries

\begin{tabular}{lllll}
\hline & CALD & LDOCE & MEDAL & OALD \\
Letter 'a' & 4300 & 4000 & 3000 & 3500 \\
Letter 's' & 6500 & 9000 & 6464 & 7000 \\
\hline
\end{tabular}

LDOCE has the largest number of headwords, followed by CALD and OALD comes third. It has to be noted however that a good number of the headwords in CALD are compounds which also appear in other sections of the wordlist. Evidently, the data in table 1 and 2 show that MEDAL has the smallest number of headwords and it uses 'etc.' much less frequently than the remaining dictionaries; this confirms its compilers' policy to keep the use of 'etc.' to a minimum. Generally, the rate of the use of 'etc.' ranges from about $5 \%$ to $10 \%$ of the total number of headwords in the four dictionaries.

\subsubsection{Frequency of occurrence of 'etc.' in individual entries}

Mostly, 'etc.' is used once in the definitions but sometimes it occurs more than once. Occasionally, more than one sense of the same headword is defined by means of 'etc.'; in such cases, it appears in two, three up to twenty senses. This illustrates how the number of headwords whose definitions contain 'etc.' is different from that of the total occurrences of 'etc.' in the definitions themselves (see table 1). To expound, here is an example where 'etc.' is used twice in the same definition.

abreast: walk/ride, etc. abreast to walk, ride, etc. next to each other, all facing the same way- two/three/four, etc. abreast ...

The statistics in table 3 below conclusively shows that LDOCE tends to use 'etc.' in one definition twice as much as all the other dictionaries; OALD comes second. Fortunately, not too many cases exist. 
Table 3: Recurrence of 'etc.' in the same definition

\begin{tabular}{lllll}
\hline & CALD & LDOCE & MEDAL & OALD \\
Letter 'a' & 6 & 45 & 13 & 12 \\
Letter 's' & 17 & 117 & 7 & 46 \\
\hline
\end{tabular}

The double use of 'etc.' in certain definitions is one of two cases. First, 'etc.' is duplicated with same preceding items as illustrated below.

spanking: when you say that sth is spanking new, etc. you are emphasizing that it is very new, etc. OALD

synthesis: the act of combining separate ideas, beliefs, styles, etc.; a mixture or combination of ideas, beliefs, styles, etc. OALD

The second occurrence of 'etc.' causes no extra trouble; 'etc.' is understood to refer to the same items in both positions. Second, 'etc.' is repeated in a different context in the remainder of the definition as illustrated below.

sight: a device that you look through to aim a gun, etc. or to look at sth through a telescope, etc. OALD

syndicate: to sell an article, a photograph, a television program, etc. to several different newspapers, etc. OALD

As indicated above, 'etc.' may appear more than twice in the same definition. The following definitions each has three occurrences of 'etc.':

adrift: two points/five seconds, etc. adrift (of somebody) two points, five seconds, etc. behind someone in a competition, race, etc.

send: RADIO/COMPUTER, ETC. to make a message, electronic signal, etc. go somewhere, using radio equipment, computers, etc.

Likewise, 'etc.' appears once or twice in the definitions of more than one sense of particular headwords. Examples:

adopt ... 2 adopt an approach/policy/attitude, etc. to start to deal with or think about something in a particular way $\mathbf{4}$ to formally approve a proposal, AMENDMENT, etc. ... 5 to choose a new name, country, custom, etc., ...

There are more and more instances of 'etc.' occurring in the explanations of more than one sense of the headword. LDOCE for example has many cases where three, four, five, six and more senses of the same headword are defined by means of 'etc.' To illustrate, three senses of each of abstract (n), adopt, adrift, apart, appear, seed, self, sequence, seal, seek, sexism, sheer, shift (v), superficial amongst others are defined by means of 'etc.' The words art, another, ask, scramble, scrape, sail, seam, supply and others have four senses each defined with 'etc.' Five senses of each of at, association, sell, success and sum are defined with 'etc.' The words sad, scope and section have some six senses each defined with 'etc.' whereas seven senses of each of set, second and scope are defined with 'etc.' The verbs 
see and shake have some ten senses defined by means of 'etc.' whereas 12 senses of each of say and season and 13 senses of send have been defined by means of 'etc.'

Table 4 lists the number of headwords whose two or more of their senses contained 'etc.' The figure is not very high in any of the four dictionaries. It should be clarified once again the figures below represent the number of headwords in which two or more of their senses have 'etc.' rather than the actual occurrences of 'etc.'; in some headwords, 'etc.' might have occurred in twenty senses and might sometimes have appeared twice in one sense. Clearly, LDOCE includes the largest number of cases; OALD comes second and CALD last, at least in the two letter stretches under examination.

Table 4: No. of headwords whose $2^{+}$of their senses contain 'etc.'

\begin{tabular}{lllll}
\hline & CALD & LDOCE & MEDAL & OALD \\
Letter 'a' & 0 & 61 & 19 & 24 \\
Letter 's' & 4 & 203 & 18 & 104 \\
\hline
\end{tabular}

However, the four dictionaries seldom coincide in their use of 'etc.' in the same lexical item. There are cases where one lexeme appears with 'etc.' in one dictionary, e.g. arriviste in OALD; two dictionaries, e.g. assault in LDOCE and OALD; three dictionaries, e.g. aspect in CALD, LDOCE and OALD and ask and sanction (n) in LDOCE, MEDAL and OALD and in all four dictionaries, e.g. armhole and author (v). Sometimes these dictionaries use 'etc.' with the same headword but each with a different sense or part of speech as in the case of scene in LDOCE, MEDAL and OALD.

Table 5 below helps us establish an accurate picture of the degree to which the four dictionaries tally in their use of 'etc.' in the same headwords, by having all the headwords cross-tabulated.

Table 5: No. of 'etc.' concurrences which tally in all four dictionaries*

\begin{tabular}{lllll|llll}
\hline & & \multicolumn{3}{c|}{ Letter 'a' } & \multicolumn{5}{c}{ Letter 's' } \\
\hline & CALD & LDOCE & MEDAL & OALD & CALD & LDOCE & MEDAL & OALD \\
CALD & $X$ & 16 & 8 & 22 & $X$ & 52 & 22 & 96 \\
LDOCE & $X$ & $X$ & 30 & 90 & $X$ & $X$ & 59 & 248 \\
MEDAL & $X$ & $X$ & $X$ & 47 & $X$ & $X$ & $X$ & 86 \\
& 74 & 291 & 132 & 220 & 234 & 624 & 196 & 723 \\
\hline
\end{tabular}

*Figures in the last row are the number of headwords containing 'etc.' (see table 1)

The figures above reveal an obvious glaring disparity within lexicographers' policies on using 'etc.' The dictionaries are so utterly disparate that they concur only in very few cases. The two dictionaries which coincide most often are LDOCE and OALD, which is possibly attributable to the fact they contain more definitions with 'etc.' than the other two. The dictionaries which coincide the 
least are CALD and MEDAL. They agree only in cases common to all four dictionaries. The 22 headwords whose definitions contain 'etc.' in all dictionaries are: absorb, adherence, ambition, armhole, at, audience and audition under 'a' and scope, score, send, set, show, side, sideboard, sign, smoke, something, send, spoiler, star, support and sweep under 's'. Not surprisingly, many of these exist in the New General Service List of the most frequent 2000 words vii (see Browne 2014). It goes without saying, the senses of the above lexemes which are defined with 'etc.' may vary from one dictionary to another and this holds true for their word classes. This again supports the contention that most lexical items can be succinctly defined without 'etc.'

Some may believe that the above is a slightly spurious argument since the comparison involved here is of headwords which had been defined using different styles and defining techniques. A more valid comparison is possibly to be drawn between dictionaries using the same defining style with the same headwords, an issue which is impossible to settle at least for the time being. One cannot actually get all dictionaries to use the same defining techniques for the same headwords as it is one of the ways that they define their competitive advantage.

\subsubsection{Number of items before 'etc.'}

Analysis has shown that the items preceding 'etc.' range from one to four. But in very limited cases, there existed five or even six items, mainly in LDOCE and MEDAL. Table 6 below lists the frequency occurrence of the items before 'etc.'

Table 6: No. of cases for each item-type before 'etc.'

\begin{tabular}{l|lllllll}
\hline \multicolumn{1}{c}{} & & $\mathbf{1}$ item & $\mathbf{2}$ items & 3 items & $\mathbf{4}$ items & $\mathbf{5}$ items & $\mathbf{6}$ items \\
\hline Letter 'a' & CALD & 5 & 38 & 35 & 6 & 0 & 0 \\
& LDOCE & 20 & 253 & 172 & 8 & 2 & 0 \\
& MEDAL & 1 & 107 & 91 & 8 & 0 & 1 \\
& OALD & 50 & 149 & 59 & 3 & 0 & 0 \\
\hline Letter 's' & CALD & 24 & 149 & 72 & 9 & 0 & 0 \\
& LDOCE & 70 & 801 & 506 & 38 & 0 & 0 \\
& MEDAL & 1 & 112 & 111 & 5 & 1 & 0 \\
& OALD & 196 & 496 & 157 & 13 & 0 & 0 \\
\hline
\end{tabular}

The figures vary in all four dictionaries. The largest figure is for the two-item type, $56 \%$ of cases, i.e. 2105 in all four dictionaries, followed by the three-item type which constituted about $32 \%$ of cases, i.e. 1203 occurrences. OALD seems to use one item before 'etc.' more often than all other dictionaries. The examples below show instances of one, two, three and four items before 'etc.'

(a) One item angry: [literary] an angry wound, etc. is painful and red and looks infected 
(b) Two items

abrogate: to officially end a legal agreement, practice, etc.

(c) Three items

above: be above suspicion/reproach/criticism, etc.

(d) Four items

accompaniment: piano, orchestra, organ, guitar, etc. accompaniment

Quite a number of the one-item cases before 'etc.' in LDOCE arise when it duplicates in the remainder of the definition (alternate: if something happens on alternate days, weeks, etc., it happens on one day, etc. and ...). As indicated above, some instances with five items before 'etc.' occurred in LDOCE as follows.

art: the arts [plural] art, music, theatre, film, literature, etc. all considered together

Similarly MEDAL, though not very often, provided some definitions with five items before 'etc.':

set: to put someone or something in a position :set someone/something in/into/on/down/back, etc.

Besides, it contained definitions with six items preceding 'etc.' as in the following definition of the noun 'act':

act: [countable] a single thing that someone does: act of violence/vandalism/terrorism/kindness/bravery/desperation, etc.

\section{Pedagogical implications}

From the above findings, one can claim that the use of 'etc.' is categorised into two types. The first type conforms to what has been suggested in the MEDAL Style Guide. That is to say, 'etc.' can be used when the items which substitute for it are easily deduced by users. For example, at accommodate (if a room, building, etc. accommodates a particular number of people ...), the remaining items seem to be easy to supply as they belong to the semantic field 'building', regardless of whether these are residential, educational, industrial, military or parking structures. Likewise, the definition of dishwasher in CALD, MEDAL and OALD as (a machine for washing plates, cups, etc) represents an acceptable use of 'etc.', since a user may easily tell what other equipment can be put in the dishwasher, e.g. 'dishes', 'glasses', 'forks', 'knives', 'pans' and possibly 'spatulas' and 'whisks'. Most dictionary users know the different types of structures which provide some room for people or the utensils which can be loaded into a dishwasher. So listing two things of the same class of items would enable dictionary users to infer the remaining names of spaces which accommodate. This seems to be a possible "pass" on the use of 'etc.' and the con- 
clusion drawn here is that 'etc.' is necessary and therefore acceptable when it represents obvious items.

Along the same lines, it can be argued that some definitions with 'etc.' can at times be reworded to dispense with 'etc.' Evidence backing up this claim emerges from definitions of the counterpart items without 'etc.' in some dictionaries. Taking some more care of the definitions which include 'etc.' can help clarify the meaning and either account for all collocates and items or make them easier to infer from context. Compare for example the different definitions of artistry:

great skill in creating or performing something, such as in writing, music, sport, etc.

CALD

the creative skill of an artist, writer, actor, or musician COBUILD

skill in a particular artistic activity LDOCE

the skill and imagination typical of an artist, writer, musician, or actor MEDAL

the skill of an artist OALD

Only CALD defines artistry with 'etc.'; the other three do not but this is only slightly different from the rest. MEDAL and COBUILD offer the same information save the point relating to sports. The other two definitions remain reasonably clear. Apparently, 'artistic activity' in LDOCE, superordinate, covers 'writing', 'acting', 'sporting', 'playing music' and others. A similar example is the word amulet which is defined with 'etc.' in all dictionaries except CALD. In the CALD definition (an object worn because it is believed to protect against evil, disease or unhappiness) the word 'unhappiness' is used in the same way as 'building' above and covers concepts such as bitterness, cheerlessness, devastation, disaffection, discontent, dismay, distress, gloom, grief, guilt and others. The COBUILD definition (a small object that you wear or carry because you think it will bring you good luck and protect you from evil or injury) may be well ahead of all others in being concise and clear.

In the second type, the gap left by 'etc.' is almost impossible to fill because the definition has an elusive quality and the user is in doubt as to the range of items which could fill the gap. Sometimes although the items before 'etc.' are in the same class, the user may find it difficult to provide the unnamed items, either because the ones before 'etc.' may be unfamiliar or there are no obvious clues as to how to fill the gap. Many of the instances examined showed that the items preceding 'etc.' had nothing in common at all. Consider the following examples:

adherence: when someone acts strictly according to rules, beliefs, etc. LDOCE succeed: to be successful in your job, earning money, power, respect, etc. OALD

The two items before 'etc.' in the first example do not belong to the same semantic field. This would perplex the user; nothing exists to enable them tell whether 'imagination', 'wish' or 'thinking' can be used instead of 'etc.' Likewise, they cannot tell whether someone acts in accordance with a parent's 'advice', 
boss's 'instructions' or friend's 'recommendation' because these are neither rules nor beliefs. The same holds true for the second example, despite containing four items before 'etc.' To demonstrate further, here are more problematic examples.

sitting: a period spent by a model who is being painted, photographed, etc. CALD

slash-and-burn: getting rid of a lot of people, systems, etc. in an organization CALD spawn: the eggs of fish, frogs, etc. CALD

What else can be used instead of 'etc.' in the first example: 'polished', 'cleaned', 'beautified', etc.? Can words such as 'documents', 'furniture', 'cars' be added to replace 'etc.' in the second example? What useful clues exist to help dictionary users decide? As for the last example, the task of dictionary users may be easier if the items which can be used instead of 'etc.' all belonged to the same semantic class. Dictionary users may need to know whether 'snakes', 'toads', 'salamanders', 'newts', 'ducks', 'birds', 'lizards', etc., which all lay eggs, could be included here. Essentially, they are confronted with one of two problems. First, the items which fill the gap do not belong to the same semantic field or share any semantic features, apart from being living creatures. In this case it would be highly likely that users fail to correctly provide the rest of the items to replace 'etc.' Second, no information exists as to restriction on the range of reference of the defined word. They may therefore give up the whole process of guessing the unnamed items.

As items before 'etc.' vary in reference and semantic fields, they may be quite confusing; it is essential that the relationship between the items commonly preceding 'etc.' is intently studied in order not to baffle the users. OALD definition of segue (to move smoothly from one song, idea, activity, condition, etc. to another) uses the superordinates 'song', 'idea', 'activity' and 'condition' which diverge considerably; this may confuse users and possibly inhibit their ability to offer any items to replace 'etc.' The same can be said about sabotage (to secretly damage or destroy equipment, vehicles, etc. that belong to an enemy or opponent, so that they cannot be used) where 'equipment' and 'vehicles' are unrelated. It is true that users can give some hyponyms of these superordinates, e.g. 'machines', 'railway lines', 'pipelines' or 'bridges' but how could they tell whether this meaning covers public or private 'property' or both? How is this different from 'vandalism'? Is it just the time at which it takes place that contributes to the distinction between the two? The list of similar examples is in fact too long and one cam keep talking about them for ages. All in all, such cases of 'etc.'-use need to be entirely abandoned so that definitions are more productive and user-friendly than ever.

In some cases where 'etc.' appears twice in the definitions, the items before 'etc.' may differ and 'etc.' itself does not refer to the same items meant in the first mention (see definitions of sight and syndicate in 4.3.3), which of course may 'add fuel to the fire' and obfuscates matters still further; the process of guessing the items which substitute for 'etc.' is thus more demanding. In most 
cases where 'etc.' is used more than once, the items before 'etc.' are repeated either in the same way or just some of them recur. However, in very few cases, more items are given in the second occurrence of 'etc.' as follows:

star: MAIN PERSON IN A FILM/PLAY, ETC. the person who has the main part, or one of them, in a film, play, show, etc. LDOCE

However, in some definitions 'etc.' seems to stand for vital information, whereas in many cases it does not; it is just redundant and seldom adds to the proper use of the defined word as appears in this definition.

abject: when someone is extremely unhappy, poor, frightened, etc. CALD

Basically, knowing more human qualities does not add to the correct use of the word 'abject'. Similarly one wonders whether adding other adjectives may contribute to the clarity of the meaning of abject. To indicate that the person is 'without hope' may be more useful than 'etc.' This and the like definitions suggest that lexicographers can sometimes dispense with 'etc.'

Dictionary writers can capitalise on those items before 'etc.' to help dictionary users as the number of items before 'etc.' may play a role in illustrating the ones to be inferred. Apparently, the more items given before 'etc.' the easier would be the task of the users; these items are expected to provide more clues to help users guess the words which stand for 'etc.' (Alzi'abi 2016). This however is not always true as there are cases where providing new items to substitute for 'etc.' remains really hard (see Nielsen 2008 for reasons why dictionary consultation may be unproductive). When only one item is listed before 'etc.', it may be an uphill task to provide correct lexemes to replace 'etc.', because no obvious clues exist to help users infer the remaining items from analogy (see also Nielsen 2008). Consider the following examples.

armoured car: a car that has special protection from bullets, etc., used especially by important people LDOCE

abstract: (technical) to make a written summary of a book, etc. OALD

spill sth out: to tell sb all about a problem, etc. very quickly; to come out quickly OALD

safeguard: a law, rule, plan, etc. that protects someone or sth from harm or problems MEDAL

One wonders whether a foreign learner with a limited world knowledge can, for example, tell what else other than 'bullets' from which an armoured car may provide special protection. Are 'missiles', 'RPG rockets' 'mortar bombs' included? Again, how can this learner tell whether a 'speech', 'short story', 'poem', 'report', 'communique', 'dictionary' or even 'film' might be abstracted? Interestingly, the last example from MEDAL does not conform to the policy of the editors which aimed at using 'etc.' in cases where the words which could follow were clear enough to be provided by the users themselves. Maybe users might be able to add words such as 'report', 'story', 'version' of something but it 
is doubtful whether they can tell what could not be used. Similar instances are far too many to cover here.

One further point to add at this juncture is the fact that dictionary users tend to stop at 'etc.' and focus on the information preceding; they ignore the part of the definition which follows (Alzi'abi 2016); the definition may contain vital information regarding the correct use of the defined item. For instance, when users stop at 'etc.' in OALD definition of appearance (an act of appearing in public, especially as a performer, politician, etc., or in court) and disregard the remainder (or in court), they miss valuable information about word usage. Dictionary editors who rely much on the use of 'etc.' have to take care of the information which appears before 'etc.' in the definition. They need to place 'etc.' at the end of the definition and make sure that more successful definitions are offered to avoid any ambiguities.

On the whole, most editors of dictionaries still insist on the use of 'etc.' Peters (2004: 190), for example, believes that using this device is much more efficient than the "wordy translations" which would replace it. It cannot be suggested, therefore, that this deeply entrenched device should be abandoned altogether at one stroke. But more care is required on their part in the use of this device where necessary.

This study was not limitation-free. One limitation was failure to access the full electronic raw data of the dictionaries, their Advanced Search facilities as well as their Style Guides to handle all definitions more easily and present a clearer and more comprehensive picture of the use of 'etc.' Had this data been accessible, more accurate figures, reliable results and hard evidence regarding the use of 'etc.' could have been obtained, let alone more valid conclusions. Although the two letter stretches scrutinised were randomly selected, some may still think that this could be an important limitation of this study as this sampling might not be optimal. Selecting the two-letter stretches, particularly the untypical 'a' letter, may be considered a bad decision for some researchers. According to some (e.g. Bukowska 2010; Cormier 2008 and Miyoshi 2007), the two-letter stretches may not be representative of the dictionary wordlist and a more systematic sampling technique should have been used.

\section{Conclusion and recommendations}

This research has thoroughly examined the use of 'etc.' in two letter stretches in four learner's dictionaries. Analysis has shown that it is used extensively in the definitions of all types of lexical items. It appears in the definitions of almost all word classes representing several linguistic patterns. Many definitions contain one occurrence of 'etc.' but there are some which have two or three occurrences. It was occasionally used many times in the definitions of headwords with multiple senses. In most cases lexicographers tend to use 'etc.' after two or three items, but sometimes either one or four items precede it.

The examination of a large number of definitions in the four dictionaries 
has shown that lexicographers are not of one mind as to the general use of 'etc.' LDOCE and OALD have been overusing this device, unlike CALD and MEDAL. This disparity in the use of 'etc.' reveals a state of considerable confusion encompassing the way 'etc.' is used. One still cannot tell why one definition has one occurrence of 'etc.' and another two or more, and why one definition has one or two items before 'etc.' and another three or four. The same holds true for the individual lexemes which are defined by means of 'etc.' in all dictionaries.

Strunk and White (1972) and Walston (2001) recommend that 'etc.' is not to be used even when the items preceding it belong to the same semantic field especially in cases where the would-be readers might be unfamiliar with items which stand for 'etc.' in a particular context. However, in the light of the above findings, lexicographers - particularly those compiling learner's dictionaries - should be encouraged to dispense with 'etc.' most of the time. They can enumerate the items which replace 'etc.', particularly when these items are not many. In case this proves impossible, they may alternatively reserve the use of 'etc.' to cases when the information is hard to cover, but they have to provide stronger pointers as to what 'etc.' stands for.

Based on the above preliminary findings, it is strongly recommended that some research be conducted to ascertain whether learners fare better when the items before 'etc.' belong to the same semantic field and whether increasing the number of items before 'etc.' correlates to the user being able to infer more lexemes to fill the 'etc.-gap' in definitions.

\section{Endnotes}

i. The theme of this article emerged from a small section about 'etc.' in dictionaries in Alzi'abi (2016).

ii. It is not the intention of this research to study the history of this linguistic unit.

iii. See www.urbandictionary.com/define.php?term=ETC.

iv. It should be reiterated that all examples were drawn from LDOCE unless otherwise indicated.

v. Although the statistics here concern OALD 8 but a quick scan of the two letter stretches in OALD 9 showed that the latter had only a few more items defined with 'etc.'

vi. These figures can never be precise unless provided by the publishers of the dictionaries.

vii. See http://www.newgeneralservicelist.org/.

\section{References}

\section{A. Dictionaries (All on DVD-ROM except those asterisked)}

Carroll, K. (Ed.). 2012. Collins COBUILD Advanced Dictionary of English. Seventh Edition. Glasgow: HarperCollins. (COBUILD7)

Deuter, M. et al. (Eds.). 2016. Oxford Advanced Learner's Dictionary. Eighth revised edition. Oxford: Oxford University Press. (OALD9) 
Higgleton, E., H. Sargent and A. Seaton (Eds.). 1992. Chambers Pocket Dictionary. Edinburgh: Chambers.

Mayor, M. (Ed.). 2009. Longman Dictionary of Contemporary English. Fifth edition. Harlow: Pearson Education. (LDOCE5)

Rundell, M. (Ed.). 2007. Macmillan English Dictionary for Advanced Learners. Second Edition. Oxford: Macmillan. (MEDAL2)

Sinclair, J. (Ed.). 1987. Collins COBUILD English Language Dictionary. London/Glasgow: HarperCollins. (COBUILD)

Summers, D. 2002. The Longman Language Activator. Second Edition. Harlow: Pearson Education.

Turnbull, J. et al. (Eds.). 2010. Oxford Advanced Learner's Dictionary of Current English. Eighth edition. Oxford: Oxford University Press. (OALD8)

Walter, E. 2008. Cambridge Advanced Learner's Dictionary. Third edition. Cambridge: Cambridge University Press. (CALD3)

\section{B. Other literature}

Alzi'abi, S.E. 1995. Missing Words and Missing Definitions: NL Arabic Speakers' Use of EFL Dictionaries. Unpublished Ph.D. Thesis. Swansea: University of Wales.

Alzi'abi, S.E. 2016. Help or Hindrance: "Etc" in Learner's Dictionaries? A Study of Verb-noun Collocations. European Journal of Applied Linguistics 4(2): 1-27.

Atkins, B.T.S. and M. Rundell. 2008. The Oxford Guide to Practical Lexicography. Oxford/New York: Oxford University Press.

Ayto, J.R. 1983. On Specifying Meaning: A Semantic Analysis and Dictionary Definitions. Hartmann, R.R.K. (Ed.). 1983. Lexicography: Principles and Practice: 89-98. Londen/New York: Academic Press.

Barnbrook, G. and J. Sinclair. 1995. Parsing Cobuild Entries. Sinclair, J., M. Hoelter and C. Peters (Eds.). 1995. The Languages of Definition: The Formalization of Dictionary Definitions for Natural Language Processing: 13-58. Luxembourg: Office for Official Publications of the Communities.

Bukowska, A.A. 2010. Sampling Techniques in Metalexicographic Research. Dykstra, A. and T. Schoonheim (Eds.). 2010. Proceedings of the XIV EURALEX International Congress: 1258-1269. Ljouwert: Afûk.

Browne, C. 2014. A New General Service List: The Better Mousetrap We've Been Looking For? Vocabulary Learning and Instruction 3(1): 1-10.

Cormier, M. 2008. Usage Labels in the Royal Dictionary (1699) by Abel Boyer. International Journal of Lexicography 21(2): 153-171.

Dziemianko, A. and R. Lew. 2006. When You are Explaining the Meaning of a Word: The Effect of Abstract Noun Definition Format on Syntactic Class Identification. Corino E., C. Marello and C. Onesti (Eds.). 2006. Proceedings of the 12th EURALEX International Congress, Torino, Italia, September 6-9, 2006: 857-863. Alessandria: Edizioni Dell'Orso.

Geeraerts, D. 2003. Meaning and Definition. Van Sterkenburg, P. (Ed.). 2003. A Practical Guide to Lexicography: 83-93. Terminology and Lexicography Research and Practice 6. Amsterdam/ Philadelphia: John Benjamins. 
Hanks, P. 1987. Definitions and Explanations. Sinclair, J. (Ed.). 1987. Looking Up: An Account of the COBUILD Project in Lexical Computing Computing and the Development of the Collins COBUILD English Language Dictionary: 116-136. London/Glasgow: Collins ELT.

Hausmann, F. and A. Gorbahn. 1989. COBUILD and LDOCE II: A Comparative Review. International Journal of Lexicography 2(1): 44-56.

Jackson, H. 2002. Lexicography: An Introduction. London/New York: Routledge.

Lew, R. 2013. Identifying, Ordering and Defining Senses. Jackson, H. (Ed.). 2013. The Bloomsbury Companion to Lexicography: 284-302. London: Bloomsbury.

Lew, R. and A. Dziemianko. 2006a. A New Type of Folk-inspired Definition in English Monolingual Learners' Dictionaries and its Usefulness for Conveying Syntactic Information. International Journal of Lexicography 19(3): 225-242.

Lew, R. and A. Dziemianko. 2006b. Non-standard Dictionary Definitions: What They Cannot Tell Native Speakers of Polish. Cadernos de Traduçao 18: 275-294.

Lew, R. and A. Dziemianko. 2012. Single-clause when-definitions: Take Three. Fjeld, R.V. and J.M. Torjusen (Eds.). 2012. Proceedings of the 15th Euralex International Congress, 7-11 August 2012, Oslo: 997-1002. Oslo: Department of Linguistics and Scandinavian Studies, University of Oslo.

Miyoshi, K. 2007. Johnson's and Webster's Verbal Examples: With Special Reference to Exemplifying Usage in Dictionary Entries. Tübingen: Max Niemeyer.

Moerdijk, F. 2003. The Codification of Semantic Information. Van Sterkenburg, P. (Ed.). 2003. A Practical Guide to Lexicography: 273-296. Amsterdam: John Benjamins.

Moon, R. 2007. Sinclair, Lexicography, and the Cobuild Project: The Application of Theory. International Journal of Corpus Linguistics 12(2): 159-181.

Nielsen, S. 2008. The Effect of Lexicographical Information Costs on Dictionary Making and Use. Lexikos 18: 170-189.

Osselton, N.E. 2007. Innovation and Continuity in English Learners' Dictionaries: The Single-clause when-definition. International Journal of Lexicography 20(4): 393-399.

Peters, P. 2004. The Cambridge Guide to English Usage. Cambridge: Cambridge University Press.

Rundell, M. 2006. More than One Way to Skin a Cat: Why Full-sentence Definitions have not been Universally Adopted. Corino E., C. Marello and C. Onesti (Eds.). 2006. Proceedings of the 12th EURALEX International Congress, Torino, Italia, September 6-9, 2006: 323-337. Alessandria: Edizioni Dell'Orso.

Sinclair, J. (Ed.). 1987. Looking Up: An Account of the COBUILD Project in Lexical Computing Computing and the Development of the Collins COBUILD English Language Dictionary. London: Collins ELT.

Strunk, W. and E. White. 1972. The Elements of Style. Second Edition. New York: Macmillan.

Van der Meer, G. 2004. On Defining: Polysemy, Core Meanings, and "Great Simplicity". Williams, G. and S. Vessier (Eds.). 2004. Proceedings of the Eleventh EURALEX International Congress, EURALEX 2004, Lorient, France, July 6-10, 2004. Vol. 2: 807-815. Lorient: Faculté des Lettres et des Sciences Humaines, Université de Bretagne Sud.

Walston, R. 2001. Coffee Talk. Today's topic: Etc., etc., etc.? http://www.Columbiaseminary.edu/ coffeetalk/035.html (accessed 9 May. 2015).

Zgusta, L. 1971. Manual of Lexicography. Janua Linguarum. Series Maior 39. The Hague: Mouton. 